\title{
Mixed methods in food risk perception
}

\author{
J. Kennedy ${ }^{1}$, A. McGloin ${ }^{1}$, A. Nolan ${ }^{1}$, E. Hudson ${ }^{1,2}$, H. Hale ${ }^{2}$, L. Delaney ${ }^{2}$ and P. G. Wall ${ }^{1}$ \\ ${ }^{1}$ School of Public Health and Population Science and ${ }^{2}$ The Geary Institute, University College Dublin, Dublin, \\ Republic of Ireland
}

Previous studies have shown that obesity levels have increased more dramatically among young men (Irish Universities Nutrition Alliance Teenager Study 2008, unpublished results) and that they are more 'at risk' from unsafe handling and preparation practices than other socio-demographic groups ${ }^{(1)}$.

Gender and education level have been identified as stratifying groupings with males and those with lower levels of education having less knowledge about safe food practices ${ }^{(2,3,4)}$ and poorer-quality eating habits ${ }^{(5,6)}$. With this specific population subgroup in mind, the aim of this study was to investigate the perceptions and attitudes of young Irish males towards nutrition and food safety.

Ten focus-group interviews ( $n$ 80) with young men from apprentice colleges (Irish National Training and Employment Authority) in the Dublin area were carried out and analysed using Atlas.ti (Atlas.ti Scientific Software Development GmbH, Berlin, Germany). Concurrently, >300 young apprentices (259 males, seventy-eight females) completed a questionnaire about nutrition and food safety knowledge, attitudes and behaviour, and data were analysed using SAS (SAS Institute Inc., Cary, NC, USA).

Themes that emerged in both the food nutrition and safety focus groups were: 'myths', 'awareness', 'risk' and 'responsibility'. Within these themes the young males demonstrated a good level of knowledge on topics such as balanced diet, physical activity, correct food preparation techniques and health consequences of poor nutrition and food hygiene. However, it was clear that the young males did not always translate this knowledge into behaviour, preferring to operate 'here and now' and 'it won't happen to me' attitudes. Key influences for both nutrition and food safety behaviour included convenience, level of hunger and the role of women.

Analysis of the quantitative data for males only revealed that most of the apprentices (77\%) considered themselves to be in good health, with $54 \%$ considering their level of activity to be healthy. Information about their diet however revealed the high intake of energy-dense foods (e.g. crisps, chocolate, sweets) with $53 \%$ reporting one to two portions per d, in comparison with the low intake of fruit and vegetables (31\% reporting none or just one portion per d). Approximately half the respondents (46\%) worried about becoming overweight. Most of the apprentices considered that they had good or very good food safety knowledge (69\%), with over half $(54 \%)$ reporting that they deal with food in a safe or very safe manner. However, three-quarters $(75 \%)$ reported that they were not the main food preparer in the household and also $63 \%$ reported having suffered from food poisoning at some stage.

While significant increases in food safety knowledge and attitudes have been reported after an educational intervention about food safety $^{(7)}$, it has also been noted that knowledge alone may not fully alter understanding and change behaviour and has been proposed that individuals tend to balance their concerns about health and safety with practicality, identity and habit ${ }^{(8)}$. Furthermore, it has been identified that the understanding of risk messages varies by demographics such as age and education level ${ }^{(9)}$. The present study contributes to the mixed-methods literature and works towards a new understanding of the phenomena and issues that young men have in the area of food in a way that has not been attainable via traditional qualitative or quantitative approaches.

1. Kennedy J, Cowan C, Blair IS et al. (2005) Br Food J 107, 441-452.

2. Brennan M, McCarthy M \& Ritson C (2007) Appetite 49, 405-418.

3. Riordan N, Cowan C \& McCarthy M (2002) J Food Safety 22, 1-15.

4. McCarthy M, Brennan M, Kelly AL et al. (2007)Food Qual Pref 18, 205-217.

4. Prattala R, Paalanen L, Grinberga D et al. (2006) Eur J Public Health 5, 520-525.

6. Roos G, Prattala R \& Koski K (2001) Appetite 37, 47-56.

7. Medeiros LC, Hillers VN, Chen G et al. (2004) J Am Diet Assoc 104, 1671-1677.

8. MacIntyre S, Reilly J, Miller D et al. (1998) Food choice, food scares and health: The role of the media. In The Nation's Diet: the Social Influence of Food Choice, pp. 228-249 [A Murcott, editor]. London: Longman.

9. DeBoer M, McCarthy M, Brennan M et al. (2005). J Food Safety 25, 241-265. 